\title{
Glomerular filtration rate change during chronic hepatitis $C$ treatment with Sofosbuvir/Ledipasvir in HCV/HIV Coinfected patients treated with Tenofovir and a boosted protease inhibitor: an observational prospective study
}

Cristina Aurora São Pedro Soeiro ${ }^{*}$, Celina Andreia Melo Gonçalves, Marta Sofia Correia Marques, Maria Josefina Vazquez Méndez, Ana Paula Ribeiro Almeida Tavares,

Ana Maria Lacerda Morgado Fernandes de Carvalho de Aboim Horta and Rui Manuel do Rosário Sarmento-Castro

\begin{abstract}
Introduction: Concomitant use of ledipasvir and boosted protease inhibitors (PIs) may increase the risk of tenofovir (TDF) nephrotoxicity, since both these drugs increase TDF levels. Our aim was to evaluate glomerular filtration rate (eGFR) evolution during HCV treatment with sofosbuvir/ledipasvir (SOF/LDV) in HCV/HIV coinfected patients, according to their antiretroviral treatment (ARV).
\end{abstract}

Methods: Observational prospective study of HCV/HIV coinfected patients treated with SOF/LDV. eGFR evolution was evaluated during and 12 weeks after HCV treatment. Patients were categorized in three groups based on ARV regimen: non TDF, non-boosted TDF and TDF + boosted PI.

Results: We included 273 patients: 145 were receiving a non-TDF regimen, 78 a non-boosted TDF scheme and 50 were receiving TDF + boosted PI. We observed a statistically significant decrease in eGFR during treatment in all groups (non TDF $p=0.03,95 \% \mathrm{Cl}[0.23-3.86]$, non-boosted TDF $p<0.01,95 \% \mathrm{Cl}$ [3.36-7.44], TDF $+\mathrm{Pl} p=0.01,95 \% \mathrm{Cl}[1.09-7.53]$ ). The decrease was more pronounced in those receiving unboosted TDF $\left(-5.40 \mathrm{ml} / \mathrm{min} / 1.73 \mathrm{~m}^{2}\right)$, but differences in eGFR decrease between the three groups were small and not statistically different $(p=0.06)$. eGFR decrease was greater in patients treated for 24 weeks $(p=0.009)$ and in cirrhotic patients $(p=0.036)$. At the end of follow up a recovery of eGFR was observed in all groups.

Conclusion: We observed a significant decrease in eGFR during treatment in all study groups, that was small and reversible after SOF/LDV discontinuation. TDF was not associated with an increase in renal toxicity.

Keywords: Co-infection HIV/HCV, HCV treatment, Sofosbuvir/ledipasvir, Renal toxicity, Tenofovir, Protease inhibitor, Drug-drug interactions

\footnotetext{
* Correspondence: cristinaaspsoeiro@hotmail.com

Infectious Diseases Department, Centro Hospitalar do Porto, Largo do Prof. Abel Salazar, 4099-001 Porto, Portugal
}

(c) The Author(s). 2018 Open Access This article is distributed under the terms of the Creative Commons Attribution 4.0 International License (http://creativecommons.org/licenses/by/4.0/), which permits unrestricted use, distribution, and reproduction in any medium, provided you give appropriate credit to the original author(s) and the source, provide a link to the Creative Commons license, and indicate if changes were made. The Creative Commons Public Domain Dedication waiver (http://creativecommons.org/publicdomain/zero/1.0/) applies to the data made available in this article, unless otherwise stated. 


\section{Background}

According to the World Health Organization (WHO), $2-15 \%$ of the people infected by the human immunodeficiency virus (HIV) are coinfected with hepatitis C virus (HCV), and this percentage goes up to $90 \%$ in those who acquired the infection through intravenous drug use [1]. Liver disease is currently one of the leading causes of morbidity and mortality in HIV infected people [2, 3] and HIV coinfected patients seem to have a faster progression to cirrhosis, a higher rate of liver decompensation and liver death and a lower response to HCV therapy [4-6]. However, HCV treatment has been shown to decrease the risk of negative outcomes even in co-infected patients [7].

With the advent of direct acting antivirals (DAAs), the sustained virologic response (SVR) rates in mono and HIV co-infected patients are similar. With these agents, high cure rates are achieved in the co-infected population, with excellent tolerability and convenient posology $[8,9]$. HIV specialists have always been aware of the importance of surveilling and managing drug-drug interactions (DDIs) between antiretroviral medication (ARV) and other co-medication. DDIs are currently one of the problems in the use of DAAs in co-infected patients [810]. Clinicians are advised to check possible DDIs between the HCV DAAs and other chronic medication, using up to date resources such as the one found at http://www.hep-druginteractions.org [8].

The association in a single tablet of sofosbuvir (SOF), a nucleotide NS5B polymerase inhibitor, and ledipasvir (LDV), an inhibitor of nonstructural protein 5A (NS5A), is one of the possible treatment options for HCV genotypes 1 and 4, and has shown impressive results in co-infected patients both in clinical trials [11] and in real life cohorts [12]. This combination has few interactions with ARV and can be used with nonnucleoside reverse transcriptase inhibitors (NNRTIs), integrase inhibitors or ritonavir-boosted HIV protease inhibitors (PIs), excluding tipranavir $[8,10]$.

However, recent studies have raised concerns regarding the interaction between LDV and tenofovir (TDF). Although the mechanism is not completely understood, it is thought that LDV increases TDF levels through the inhibition of P-glycoprotein (P-gp) and breast cancer resistance protein (BCRP) [13]. Moreover, it has been shown that TDF exposure is even greater (30-60\%) when SOF/LDV was co-administered with a boosted PI [14]. As administration of TDF with a boosted PI already increases TDF by $20-30 \%$, most authors and guidelines recommend changing ARV or DAA therapy; if, however, this triple combination must be used, renal function should be closely monitored [13, 15-17]. In those with a glomerular filtration rate $<60 \mathrm{~mL} / \mathrm{min}$, these drugs should be avoided [13, 15-17].
The aim of our study was to evaluate the effect of the combination SOF/LDV in the eGFR in HCV/HIV patients who were receiving TDF as part of their antiretroviral therapy, and to analyze the added risk of the concomitant use of a boosted PI.

\section{Methods}

This was a single center observational prospective study regarding all $\mathrm{HCV} / \mathrm{HIV}$ patients treated with DAAs in our department. Data on baseline characteristics, co-morbidities, medication and evolution during $\mathrm{HCV}$ treatment was collected in a database that was previously approved by the hospital's ethical commission, as well as by the National Data Protection Commission. Informed consent was obtained for all patients.

We analyzed the data of those patients who were treated with SOF/LDV for HCV and who had completed at least 12 weeks of follow up after treatment, from February 2015 to July 2017; patients who did not complete 12 weeks of follow up after treatment were excluded (death or abandonment) as well as patients with incomplete records. Patients were categorized in three groups according to their ARV regimen: (1) non TDF containing regimen (non TDF), (2) TDF without a boosted PI (non-boosted TDF) or (3) TDF with a ritonavir boosted PI (boosted TDF). Evolution of estimated glomerular filtration rate (eGFR) during and after HCV treatment was compared amongst the three groups. eGFR was calculated using the Chronic Kidney Disease Epidemiology Collaboration (CKD-EPI) formula.

Statistical analysis was performed using Statistical Package for the Social Sciences $\left(\mathrm{SPSS}^{\odot}\right)$ software, version 23. Paired t- test was used for comparing baseline and end of treatment (EOT) mean eGFR evolution in each group, likelihood ratio was used for categorical variable analysis, ANOVA for analysis of mean difference within the 3 groups and Wilcoxon signed-rank test to evaluate the impact of cirrhosis in the eGFR. $P$-value $<0.05$ was defined as statistically significant.

All patients in our cohort were evaluated for liver fibrosis using transient hepatic elastography (Fibroscan ${ }^{\odot}$ ) and, in some cases, liver biopsy. Patients with an hepatic elastrography value $\geq 12.5 \mathrm{KPa}$ were considered cirrhotic.

\section{Results}

From February 2015 until July 2017, 333 HCV/HIV coinfected patients were treated for chronic $\mathrm{HCV}$ infection in our department. Of these, 273 (81.9\%) were prescribed the combination SOF/LDV for 12-24 weeks and completed 12 weeks of follow up. We excluded 19 patients from our analysis (three died during HCV treatment, three were lost to follow up and 13 had incomplete records). 
All the $273 \mathrm{HCV} / \mathrm{HIV}$ patients were receiving antiretroviral medication: $53.1 \%(n=145)$ received a non-TDF regimen, 28.6\% $(n=78)$ used an unboosted TDF scheme and TDF plus boosted PI was administered in $18.3 \%(n=50)$. Efavirenz was the most used third agent in both the non-TDF and unboosted-TDF groups $(n=50,34,5 \%$ and $n=52,66,7 \%$, respectively); other drugs less used included rilpivirine ( $n=2,1,4 \%$ and $n=6,7,7 \%$ respectively) and dolutegravir ( $n=10,6,9 \%$ and $n=1,1,3 \%$, respectively). Regarding the TDF + PI group, the most frequently used boosted PI was darunavir ( $n=27,54 \%)$, followed by atazanavir $(n=14,28 \%)$ and finally lopinavir $(n=9,18 \%)$; ritonavir was the booster used in all cases.

The baseline characteristics of the three groups (non-TDF, non-boosted TDF and with TDF + PI) are shown in Table 1. Almost all patients had undetectable HIV RNA $(n=258,94.5 \%)$ and the mean CD4 cell count was $650 / \mathrm{mm}^{3}\left( \pm 338 / \mathrm{mm}^{3}\right)$.

The mean baseline eGFR was $100.9 \mathrm{ml} / \mathrm{min} / 1.73 \mathrm{~m}^{2}$ $( \pm 16.3)$ in the non TDF group, $104.1 \mathrm{ml} / \mathrm{min} / 1.73 \mathrm{~m}^{2}$ $( \pm 11.3)$ in non-boosted TDF and $98.2 \mathrm{ml} / \mathrm{min} / 1.73 \mathrm{~m}^{2}( \pm$ 11.8) in the TDF + boosted PI group. In all groups, we observed a decrease in eGFR during treatment, as is shown in Fig. 1.

The decrease of eGFR between the baseline and the end of treatment (EOT) was statistically significant in all groups (non TDF $p=0.03,95 \%$ CI [0.23-3.86], non-boosted TDF $p<0.01,95 \%$ CI [3.36-7.44], TDF + PI $p=0.01,95 \%$ CI [1.09-7.53]). The decrease was more pronounced in those receiving unboosted TDF (mean difference $5.40 \mathrm{ml} / \mathrm{min} / 1.73 \mathrm{~m}^{2}$; $95 \% \mathrm{CI} \quad[(-7.44) \quad-(-$ $3.37)])$, than in those receiving either TDF + boosted PI (mean difference $4.31 \mathrm{ml} / \mathrm{min} / 1.73 \mathrm{~m}^{2} ; 95 \% \mathrm{CI}[(-7.53)$ $-(-1.09)]$ or non TDF regimens (mean difference $\left.2.02 \mathrm{ml} / \mathrm{min} / 1.73 \mathrm{~m}^{2} ; 95 \% \mathrm{CI}[(-3.84)-(-0.02)]\right)$. Differences in eGFR decrease between the three groups were small and were not statistically different $(p=0.06)$. (Table 2).

At the end of follow up a recovery of eGFR was observed in all groups (Fig. 1).

The evolution of eGFR was similar between those who were treated for 12 weeks $(n=188)$ to those treated for 24 weeks $(n=85)$. However, there was a steeper decrease in eGFR in those who receiving a longer treatment course: mean change was $-2.195 \% \mathrm{CI}$ $[(-3.43)-(-7.96)]$ in those treated for 12 weeks and $-6.3 \mathrm{ml} / \mathrm{min} / 1.73 \mathrm{~m}^{2}$ 95\%CI $[(-9.08)-(-3.47)]$ in those treated for 24 weeks $(p=0.009)$. There was a statistical significant difference in mean eGFR decrease amongst the three ARV groups in those treated for 24 weeks $(p=0.026)$, but not in those who were treated for 12 weeks $(p=0.89)$. Of note, there was a higher proportion of cirrhotic patients in those treated for 24 weeks $(81.2 \%$ of patients treated for this duration, $n=$ 69) than in those treated for 12 weeks $(13.3 \%$ of patients treated for 12 weeks, $n=25$ ).

A separate analysis of the 94 cirrhotic patients included showed a similar evolution. There were no differences amongst the three groups $(p=0.833)$. However, cirrhosis was associated with a decrease in eGFR $(p=0.036)$ : mean eGFR decrease for cirrhotic patients was $-5.57 \mathrm{ml} / \mathrm{min} / 1.73 \mathrm{~m}^{2} \quad(95 \% \mathrm{CI} \quad[(-8.16)$ $-(-2.98)])$ vs $-2.28 \mathrm{ml} / \mathrm{min} / 1.73 \mathrm{~m}^{2}$ (95\%CI [(-3.64) $-(-0.91)]$ for non-cirrhotic patients.

Table 1 Baseline characteristics of patients according to ARV regimen

\begin{tabular}{|c|c|c|c|c|}
\hline Baseline characteristics & Non TDF $n=145$ & Non-boosted TDF $n=78$ & TDF + Boosted PI $n=50$ & p \\
\hline Male, $n,(\%)$ & $127(87.6)$ & $67(85.9)$ & $45(90.0)$ & 0.78 \\
\hline Mean age \pm SD (years) & $47 \pm 6$ & $47 \pm 6$ & $45 \pm 6$ & 0.79 \\
\hline Baseline mean creatinine $\pm \mathrm{SD}(\mathrm{mg} / \mathrm{dL})$ & $0.84 \pm 0.19$ & $0.8 \pm 0.13$ & $0.9 \pm 0.14$ & 0.05 \\
\hline Baseline mean $\mathrm{eGFR} \pm \mathrm{SD}\left(\mathrm{ml} / \mathrm{min} / 1.73 \mathrm{~m}^{2}\right)$ & $100.9 \pm 16.3$ & $104.1 \pm 11.3$ & $98.2 \pm 11.8$ & 0.06 \\
\hline Body mass index $\pm \mathrm{SD}\left(\mathrm{Kg} / \mathrm{m}^{2}\right)$ & $23.3 \pm 3.9$ & $22.3 \pm 4.3$ & $22.8 \pm 3.8$ & 0.24 \\
\hline Diabetes, n (\%) & $5(3.4)$ & $4(5.1)$ & $1(2.0)$ & 0.63 \\
\hline Hypertension, $n$ (\%) & $21(14.5)$ & $10(12.8)$ & $4(8.0)$ & 0.47 \\
\hline Median $\mathrm{CD}^{+}$cell count \pm IQ $\left(/ \mathrm{mm}^{3}\right)$ & $618(457-868)$ & $611(443-762)$ & $506(279-807)$ & 0.12 \\
\hline VL HIV < 20 cp/mL, n (\%) & $138(95.2)$ & $76(97.4)$ & $44(88)$ & 0.09 \\
\hline Median stiffness \pm IQ (kPa) & $9.4(6.4-15.4)$ & $9.5(6.9-12.3)$ & $10.5(7.4-18.2)$ & 0.74 \\
\hline Cirrhosis, $n(\%)$ & $53(36.6)$ & $19(24.4)$ & $22(44.0)$ & 0.051 \\
\hline Median MELD \pm IQ & $7(6-8)$ & $7(6-7)$ & $7(7-9)$ & 0.07 \\
\hline Child-Pugh A, n (\%) & $33(62.2)$ & $8(42.1)$ & $9(40.9)$ & 0.10 \\
\hline SOF/LDV 24 weeks, $n$ (\%) & $42(27.2)$ & $24(30.0)$ & $19(38.0)$ & 0.50 \\
\hline Ribavirin use, $n$ (\%) & $28(18.4)$ & $14(17.5)$ & $9(18.0)$ & 0.96 \\
\hline
\end{tabular}

TDF tenofovir, PI protease inhibitor, Non TDF regimens without TDF, Non-boosted TDF regimens with TDF without boosted PI, TDF Boosted PI - regimens with TDF and boosted PI, SD standard deviation, IQ interquartile range, VL viral load, MELD Model for End-Stage Liver Disease score, SOF sofosbuvir, LDV ledipasvir 


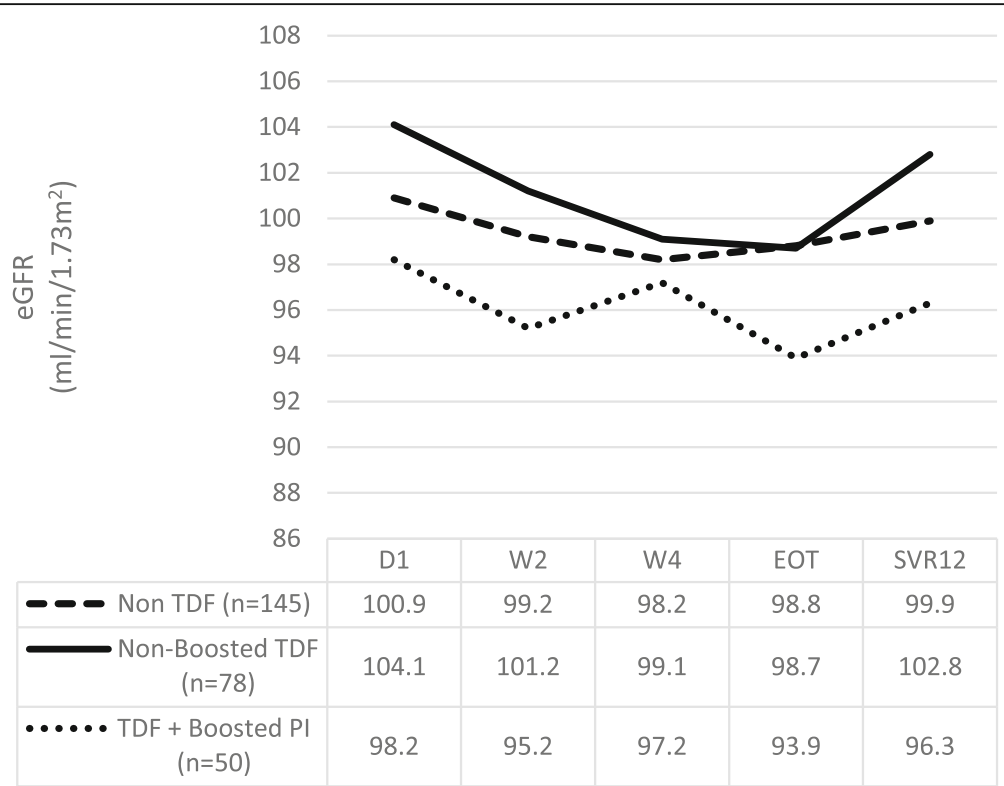

Fig. 1 Evolution of the eGFR during treatment and at SVR12 according to ARV regimen. (eGFR - estimated glomerular filtration rate; D1 - day 1 , beginning of treatment; W2 - week 2 of treatment; W4 - week 4 of treatment; EOT - end of treatment; SVR12 - end of follow up; TDF - tenofovir; PI - protease inhibitor; Non TDF - regimens without TDF; Non-boosted TDF - regimens with TDF without boosted Pl; TDF + Boosted PI - regimens with TDF and boosted PI)

There were six patients whose eGFR decreased to less than $60 \mathrm{ml} / \mathrm{min} / 1.73 \mathrm{~m}^{2}$ during $\mathrm{HCV}$ treatment, but, except for one patient in the non-TDF group, these decreases were transient and were not sustained in the following assessments. The evolution of these patients is shown in Table 3.

No patient needed to interrupt HCV treatment due to renal dysfunction and no patient changed ARV during HCV treatment. The SVR12 was 98.6, 98.7 and 100\% for the non-TDF, the unboosted TDF and boosted TDF group, respectively.

\section{Discussion}

The SOF/LDV combination pill is an option for the treatment of HCV genotypes 1 and 4, due to its simple posology, good tolerability and few DDIs. However, international guidelines recommend caution (and frequent renal monitoring) when using these drugs in HIV coinfected patients receiving TDF and a booster (either ritonavir or cobicistat) as part of their ARV regimen due to the increased risk of TDF exposure and renal toxicity $[15,16]$.
In our cohort of SOF/LDV treated $\mathrm{HCV} / \mathrm{HIV}$ co-infected patients, receiving multiple of ARV therapeutic schemes which included regimens without TDF, with TDF and TDF combined with a ritonavir boosted PI, we observed a significant decrease in eGFR during treatment in all study groups. The eGFR decrease was more pronounced in those patients receiving TDF in comparison with patients receiving either TDF with a boosted PI or non-TDF containing regimens, but the changes were small in all groups and had little clinical impact. Moreover, we found no statistical differences amongst the three groups regarding comorbidities. We found no explanation for the grater decrease in eGFR in the unboosted TDF group. Treatment duration had an impact in eGFR decrease, with longer treatment courses being associated with greater eGFR decrease. However, the proportion of cirrhotic patients was much higher in the group of patients treated for 24 weeks $(81.2 \%)$ and cirrhosis was also associated with a decrease in eGFR $(p=0.036)$.

Despite this overall decrease, after treatment completion eGFR returned to almost baseline values in all

Table 2 Global Mean eGFR decrease between the baseline and end-of-treatment

\begin{tabular}{llll}
\hline Global Mean eGFR Decrease between the baseline and EOT & & $p$ & Confidence Interval \\
\hline Non TDF $n=152$ & $5.40 \mathrm{ml} / \mathrm{min}^{\prime} / 1.73 \mathrm{~m}^{2}$ & 0.03 & $95 \% \mathrm{Cl}[(-7.44)-(-3.37)]$ \\
Non-boosted TDF $n=80$ & $4.31 \mathrm{ml} / \mathrm{min} / 1.73 \mathrm{~m}^{2}$ & $<0.01$ & $95 \% \mathrm{Cl}[(-7.53)-(-1.09)]$ \\
TDF + Boosted PI $n=50$ & $2.02 \mathrm{ml} / \mathrm{min} / 1.73 \mathrm{~m}^{2}$ & 0.01 & $95 \% \mathrm{Cl}[(-3.84)-(-0.02)]$
\end{tabular}

TDF tenofovir, PI protease inhibitor, Non TDF regimens without TDF, Non-boosted TDF regimens with TDF without boosted PI, TDF Boosted PI - regimens with TDF and boosted $\mathrm{PI}, E O T$ end of treatment 
Table 3 Evolution of the eGFR in patients with eGFR below $60 \mathrm{ml} / \mathrm{min} / 1.73 \mathrm{~m}^{2}$ during treatment

\begin{tabular}{|c|c|c|c|c|c|c|c|c|}
\hline & Group & Gender, Age & Cirrhosis & $\begin{array}{l}\text { HCV Treatment } \\
\text { Duration }\end{array}$ & $\begin{array}{l}\text { eGFR at baseline } \\
\left(\mathrm{ml} / \mathrm{min} / \mathrm{m}^{2}\right)\end{array}$ & $\begin{array}{l}\text { eGFR at } \mathrm{W} 4 \\
\left(\mathrm{ml} / \mathrm{min} / \mathrm{m}^{2}\right)\end{array}$ & $\begin{array}{l}\text { eGFR at EOT } \\
\left(\mathrm{ml} / \mathrm{min} / \mathrm{m}^{2}\right)\end{array}$ & $\begin{array}{l}\text { eGFR at SVR12 } \\
\left(\mathrm{ml} / \mathrm{min} / \mathrm{m}^{2}\right)\end{array}$ \\
\hline 1 & Non-TDF & Male, 66 yo & Yes & $12 w$ & 59 & 45.3 & 56.9 & 63.9 \\
\hline 2 & Non-TDF & Male, 48 yo & Yes & $24 w$ & 60 & 62.8 & 54.3 & 57.5 \\
\hline 3 & Non-TDF & Male, 49 yo & Yes & $24 w$ & 65.9 & 57.1 & 37.8 & 32 \\
\hline 4 & Non-TDF & Male, 55 yo & Yes & $12 w$ & 67.7 & 62 & 59.8 & 57.7 \\
\hline 5 & Non-boosted TDF & Male, 55 yo & Yes & $24 w$ & 72.8 & 57.7 & 60.9 & 71.2 \\
\hline 6 & TDF+ Boosted PI & Male, 45 yo & Yes & $24 w$ & 80.6 & 64.1 & 57.7 & 83.4 \\
\hline
\end{tabular}

eGFR estimated glomerular filtration rate, W2 week 2 of treatment, W4, week 4 of treatment, EOT end of treatment, SVR12 end of follow up, TDF tenofovir, PI protease inhibitor, Non-TDF regimens without TDF, Non-boosted TDF regimens with TDF without boosted PI, TDF Boosted PI - regimens with TDF and boosted PI, yo years old, $w$ week

groups. We observed the same occurrence in those who had a longer course of treatment and in cirrhotic patients. No patient needed to interrupt HCV treatment due to renal dysfunction and there were no ARV alterations; the SVR12 was above $98 \%$ in all groups.

Our results are consistent with the already published literature. Bhattacharya and colleagues analysed a cohort of $996 \mathrm{HCV}$ genotype 1 and HIV co-infected patients, of which 895 were treated with SOF/LDV \pm $\mathrm{RBV}$; these authors did not find any difference in creatinine change during SOF/LDV treatment in those receiving either TDF containing ARV schemes (with or without PI) or those not receiving TDF [18]. Moreover, in line with our results, the median creatinine change was small $(0.15 \mathrm{mg} / \mathrm{dL}$ in those without TDF, $0.18 \mathrm{mg} / \mathrm{dL}$ with TDF and $0.17 \mathrm{mg} / \mathrm{dL}$ in those with $\mathrm{TDF}+\mathrm{PI}$ ) and not different between the three groups $(p=0.30)$ [18].

Taramasso et al. evaluated the renal tolerability of the SOF/LDV in patients participating in the SCOLTA project (Surveillance Cohort Long-Term Toxicity Antiretrovirals), which included $79 \mathrm{HCV} / \mathrm{HIV}$ co-infected patients: 47 taking TDF, 34 a ritonavir boosted PI and 17 TDF + boosted PI [19]. The authors found no statistically significant variation of eGFR in patients receiving a boosted PI either in combination with TDF or not [19]. Moreover, they observed that patients receiving unboosted TDF experienced the highest percentage of filtration loss $(-5.3 \mathrm{~mL} / \mathrm{min}(\mathrm{SD} \mathrm{15.8)})$ and that the frequency of eGFR loss $>5 \%$ was more frequent in this group but similarly to our results, there was no difference between those who took a boosted PI and those who did not [19].

Despite these reassuring results, Bunnell and colleagues published a case of acute tubular necrosis and acute interstitial nephritis in a HCV/HIV co-infected patient taking efavirenz/tenofovir/emtricitabine and receiving $\mathrm{HCV}$ treatment with SOF/LDV, that resolved after discontinuation of TDF and SOF/LDV [20]. Of note, the patient was also taking other medications that could contribute to renal injury [20].
The main limitations of our study are its observational nature and the lack of analysis of other parameters of renal lesion, namely urine analysis, proteinuria, albuminuria, as well as serum and urinary measurements of calcium and phosphate. Moreover, we did not evaluate the impact of other possible causes of nephrotoxicity. Additionally, data regarding HIV and HCV history is lacking, due to the lack of informatic records in our hospital.

The ongoing clinical trial NCT02588287 (Effects of Sofosbuvir/Ledipasvir Treatment on the Pharmacokinetics and Renal Safety of Tenofovir), promoted by the University of Colorado, is likely to shed some more light on the safety of this combination [21].

\section{Conclusion}

We observed a decrease in the mean GFR in all patients treated with SOF/LDV. This decrease was higher in those receiving TDF, but the differences amongst the three groups were small and not statistically significant. Moreover, the eGFR decrease seems to be reversible after termination of $\mathrm{HCV}$ treatment. Our data, along with that of other authors [18, 19], reassures clinicians on the safety of SOF/LDV in combination with TDF containing regimens, regardless of the concomitant use of a boosted PI. However, from the authors point of view and as recommended in guidelines, if TDF is used in patients who are receiving SOF/LDV, signs of nephrotoxicity should be carefully monitored $[15,16]$, especially in cirrhotic patients.

\section{Abbreviations \\ ARV: Antiretroviral medication; DAA: Direct acting antiviral; DDls: Drug-drug interactions; eGFR: estimated Glomerular filtration rate; EOT: End of treatment; HCV: Hepatitis C virus; HIV: Human immunodeficiency virus; LDV: Ledipasvir; NNRTI: Nonnucleoside reverse transcriptase inhibitor; PI: Protease inhibitor; SOF: Sofosbuvir; SVR: Sustained virologic response; TDF: Tenofovir; WHO: World Health Organization}

\section{Acknowledgements}

The authors thank Dr. J. Seabra, Dr. O. Vasconcelos, Dr. M. Abreu, Dr. M. Gonçalves and Enf. M. Santos.

\section{Availability of data and materials}

All data generated or analysed during this study are included in this published article. The datasets generated and/or analysed during the current study are 
not publicly available, in accordance with the recommendation of the National Commission for Data Protection. Data are however available from the authors upon reasonable request and with permission of the National Commission for Data Protection, Hospital Ethical Committee and Head of Department.

\section{Authors' contributions}

CS - Manuscript writing and preparation, data collection, data analysis and interpretation. CG - Manuscript writing and preparation, data collection, data analysis and interpretation. MM - Data collection and analysis. JM - Manuscript preparation, data analysis and interpretation. APT - Data collection and analysis. AH - Data collection and analysis. RSC - Manuscript preparation, data analysis and interpretation. All authors have read and approved the manuscript.

\section{Ethics approval and consent to participate}

This study was approved by the Ethical Commission of Centro Hospitalar do Porto and by the Portuguese National Data Protection Commission. Written informed consent was obtained for all patients.

\section{Consent for publication}

All authors agreed with the final manuscript and consented publication. Participants consented publication.

\section{Competing interests}

The authors declare that they have no competing interests.

\section{Publisher's Note}

Springer Nature remains neutral with regard to jurisdictional claims in published maps and institutional affiliations.

Received: 28 November 2017 Accepted: 27 July 2018

Published online: 03 August 2018

\section{References}

1. World Health Organization. http://www.who.int/hiv/topics/hepatitis. Accessed July 2017.

2. Smith CJ, Ryom L, Weber R, Morlat P, Pradier C, Reiss P, et al. Trends in underlying causes of death in people with HIV from 1999 to 2011 (D:a:D): a multicohort collaboration. Lancet. 2014;384:241-8.

3. Weber R, Ruppik M, Rickenbach M, Spoerri A, Furrer H, Battegay M, et al. Decreasing mortality and changing patterns of causes of death in the Swiss HIV cohort study. HIV Med. 2013;14:195-207.

4. Re LR, Kallan MJ, Tate JP, Localio AR, Lim JK, Goetz MB, et al. Hepatic decompensation in antiretroviral-treated HIV/hepatitis C-Coinfected compared to hepatitis C-Monoinfected patients: a cohort study. Ann Intern Med. 2014;160(6):369-7.9

5. Graham CS, Baden LR, Yu E, Mrus JM, Carnie J, Heeren T, et al. Influence of human immunodeficiency virus infection on the course of hepatitis $C$ virus infection: a meta-analysis. Clin Infect Dis. 2001;33(4):562-9.

6. Chen JY, Feeney ER, Chung RT. HCV and HIV co-infection: mechanisms and management. Nat Rev Gastroenterol Hepatol. 2014;11:362-71.

7. Mira JA, Rivero-Juárez A, López-Cortés LF, Girón-González JA, Téllez F, de los Santos-Gil I, et al. Benefits from sustained virologic response to pegylated interferon plus ribavirin in HIV/hepatitis C virus-coinfected patients with compensated cirrhosis. Clin Infect Dis. 2013;56:1646-53.

8. Arends JE, Lieveld FI, Boeijen LL, Kanter CTMM, Erpecum KJ, Salmon D, et al, Natural history and treatment of HCV/HIV coinfection: is it time to change paradigms? J Hepatol. 2015;63:1254-62

9. Cachay E, Soriano V. Is HIV still a special population for the treatment of hepatitis C? AIDS. 2016:30(12):2001-3.

10. Langness J, Larson B, Bayer J, Rogers M, Kiser J. Readying HIV/HCV coinfected patients for HCV treatment: occurrence and management of antiviral interactions. In: 16th International Workshop on Clinical Pharmacology of HIV and Hepatitis Therapy. 2015, Washington. Abstract 18. http://regist2.virology-education.com/2015/16HIVHEP/34_Langness.pdf. Accessed Dec 2016.

11. Naggie S, Cooper C, Saag M, Workowski K, Ruane P, Towner WJ, et al. Ledipasvir and Sofosbuvir for HCV in patients Coinfected with HIV-1. N Engl J Med. 2015:373:705-13.

12. Butt AA, Yan P, Shaikh OS, Chung RT, Sherman KE. Sofosbuvir-based regimens in clinical practice achieve SVR rates closer to clinical trials: results from ERCHIVES. Liver Intent. 2016;36:651-8.
13. El-Sherif $\mathrm{O}$, Khoo S, Solas C. Key drug-drug interactions with direct-acting antiviral in HIV-HCV coinfection. Curr Opin HIV AIDS. 2015;10:348-54

14. German P, Garrison K, Pang PS, Stamm LM, Ray AS, Shen G, et al. Drug-Drug Interactions Between Anti-HCV Regimen Ledipasvir/Sofosbuvir and Antiretrovirals. In: Conference on Retroviruses and Opportunistic Infections. 2015, Seattle. Abstract 82. http://www.croiconference.org/sessions/drugdrug-interactions-between-anti-hcv-regimen-ledipasvirsofosbuvir-andantiretrovirals. Accessed Dec 2016.

15. European Association for the Study of the Liver. EASL recommendations on treatment of hepatitis C 2016. J Hepatol. 2017;66:153-94.

16. AASLD/IDSA HCV Guidance Panel. AASLD-IDSA recommendations for testing, managing, and treating adults infected with hepatitis $C$ virus. http://www.hcvguidelines.org. Accessed July 2017.

17. Kaur K, Gandhi MA, Slish J. Drug-Drug Interactions Among Hepatitis C Virus (HCV) and Human Immunodeficiency Virus (HIV) Medications. Infect Dis Ther. 2015;4:159-72

18. Bhattacharya D, Belperio PS, Shahoumian TA, Loomis TP, Goetz MB, Mole LA, et al. Effectiveness of All-Oral Antiviral Regimens in 996 Human Immunodeficiency Virus/Hepatitis C Virus Genotype 1-Coinfected Patients Treated in Routine Practice. Clin Infect Dis. 2017:64(12):1711-20.

19. Taramasso L, Ricci E, Celesia BM, Bonfanti P, Quirino T, Squillace N, et al. Coadministration of tenofovir plus protease inhibitor based antiretroviral therapy during sofosbuvir/ledipasvir treatment for HCV infection: much ado about nothing? Clin Res Hepatol Gastroenterol. 2017:S2210-7401(17):30085-2.

20. Bunnell KL, Vibhakar S, Glowacki RC, Gallagher MA, Osei AM, Huhn G. Nephrotoxicity associated with concomitant use of Ledipasvir-Sofosbuvir and Tenofovir in a patient with hepatitis $C$ virus and human immunodeficiency virus coinfection. Pharmacotherapy. 2016;36(9):e148-53.

21. ClinicalTrials.gov. Effects of Sofosbuvir/Ledipasvir Treatment on the Pharmacokinetics and Renal Safety of Tenofovir. https://clinicaltrials.gov/ct2/ show/NCT02588287. Accessed July 2017.

Ready to submit your research? Choose BMC and benefit from:

- fast, convenient online submission

- thorough peer review by experienced researchers in your field

- rapid publication on acceptance

- support for research data, including large and complex data types

- gold Open Access which fosters wider collaboration and increased citations

- maximum visibility for your research: over $100 \mathrm{M}$ website views per year

At $\mathrm{BMC}$, research is always in progress.

Learn more biomedcentral.com/submissions 